\title{
Drag kings in Cape Town: The performance of gendered subjectivities online
}

\author{
Mooniq Shaikjee \\ University of the Western Cape
}

\begin{abstract}
The last few decades have seen the development of a large body of scholarly work on drag queens and performances of femininity by men (see Barrett 1995, 1999). However, performances of masculinity by women have largely been overlooked. Research by scholars like Judith Halberstam (1997, 1998) on female masculinity and the drag king performer has attempted to address this imbalance, but the phenomenon has yet to receive any attention from sociolinguists. This study aims to bring attention to online performances of masculinity by women in the South African context through a multimodal analysis of the Facebook pages of performers in the country's first known drag king troupe, Bros B4 Ho's. The study has three broad aims: firstly, to demonstrate the way in which the process of entextualisation is used as a key resource in the kings' performances of masculinity online; secondly, to demonstrate that the masculinities put on display during these events are 'queer subject position[s] that can successfully challenge hegemonic models of gender conformity' (Halberstam 1997, 9); and thirdly, to argue that what the kings do is not always a straightforward disruption of heteronormative masculinity - at times they reproduce and reinforce the very structures they seek to critique.
\end{abstract}

Keywords: Gender, Drag kings, Multimodality, Facebook, Entextualisation, South Africa

\section{INTRODUCTION}

T he last few decades have seen the development of a large body of scholarly work on drag queens and performances of femininity by men (see Barrett 1995, 1999). However, performances of masculinity by women have largely been overlooked. Research by Judith Halberstam (1997, 1998, 2001) on female masculinity and the drag king performer has attempted to address this imbalance, but the phenomenon has yet to receive any attention from sociolinguists. According to Halberstam (1997), a drag king is most often (but not always) a female who dresses up in costume that is recognizably masculine, and who performs theatrically in that costume. The intention is not simply to mimic or imitate men, but to parody and disrupt mainstream, dominant forms of masculinity.

This paper will analyse the Facebook activity and online gender performances of the members of Cape Town's first 
known drag king troupe, Bros B4 Ho's. The study forms part of a broader project which analyses the group's online activity alongside their stage performances. In the years since Judith Halberstam's research on drag kings was conducted, the internet has revolutionised the way we communicate and share information. Social networking sites like Facebook and Twitter have exploded in popularity, and provide interesting new arenas for individuals to explore identity performance. Extending the research site to include an online environment has allowed for insight into how social actors use the semiotic resources available to them on this platform, and has also supplied texts in which they explain their actions and frame their practices in certain ways.

The study aims to demonstrate that entextualisation works as an important resource for drag king performers to perform their gendered subjectivities on an online platform, and that the masculinities put on display during these events are "queer subject position[s] that can successfully challenge hegemonic models of gender conformity' (Halberstam 1997, 9). I would also like to argue that what the drag kings in this study do is not always a straightforward disruption of heteronormative masculinity; at times they reproduce and reinforce the very structures they seek to critique. In doing so, I would like to interrogate Halberstam's definition of female masculinity as a purely subversive phenomenon.

\section{Background - Bros B4 Ho's}

In November 2011, after attending a performance by drag king Johnny Deep at Bubbles Bar in Cape Town, Catherine Saint Jude Pretorius decided to create her own drag king persona, rapper Saint Dude. Following a few successful performances at the open stage nights at Bubbles, and realising that other women may also benefit from the catharsis she experienced while performing, Pretorius put out an invitation on the Facebook group 'Cape Town Lesbians' for a gathering to discuss the possible formation of a drag king troupe. By the end, four women and a transgender man had decided to create personas and perform as part of the collective that would later become known as Bros B4 Ho's.

The kings began performing in pairs at Bubbles Bar's open mic nights and quickly gained quite a following. They organised their first sit-down event at Obz Cafe in June 2012 with the help of a burlesque group called Black Orchid Burlesque. Their second formal show took place in December 2012 at Alexander Bar. At the time the data for this study was collected, the six personas regularly performed by the group were troupe leader Saint Dude, FreDDie, Umlilo John, King Cory Lingus, Frankie $\mathrm{H}$ and Cole Steel Johnson.

\section{THEORETICAL FRAMEWORK}

\section{Gender, drag and female masculinity}

The past few decades have seen a change in the way sex, gender and sexuality have been conceptualised in the social sciences (see Baker, 2008). There has been a shift away from conflating biological sex and gender, and then mapping this directly onto sexuality. In her work on gendered discourses, Jane Sunderland explains that gender is different to sex in that it refers only to differences between men and women that are 'socially or culturally learned, mediated or constructed' (2004: 14). In other words, gender is not an 


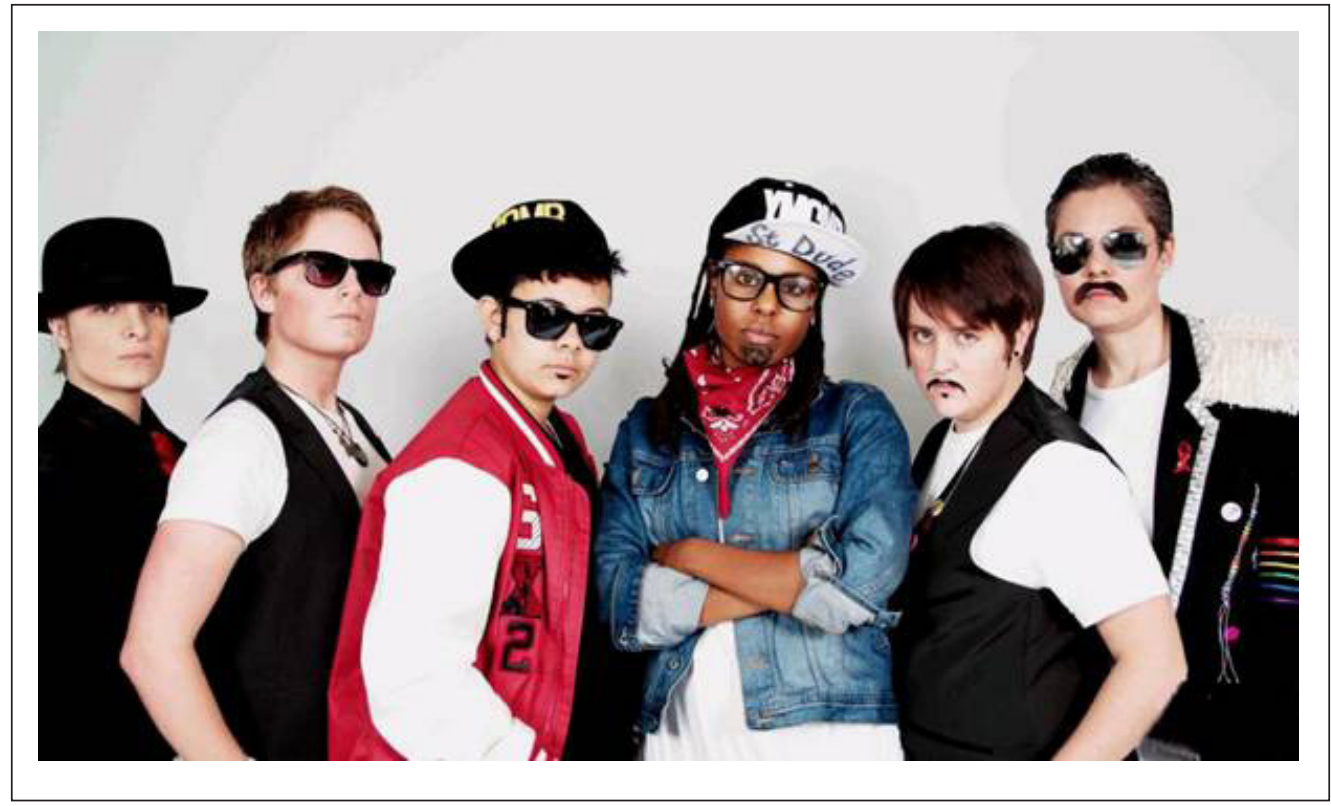

Figure 1 - Bros B4 Ho's (From left to right: Cole Steel Johnson, Frankie H, Umlilo John, Saint Dude, King Cory Lingus and FreDDie)

innate quality that individuals are born with, but something which we learn to embody throughout our lives. At the same time, the terms 'man' and 'woman' have also been problematised, as they homogenise men and women by placing them into two monolithic categories and presenting the differences between the two in binary opposition. Baker breaks this binary down further by explaining that all people exist on a 'gendered continuum' (2008: 63) rather than in two distinct, mutually exclusive groups, and their place on the continuum can shift in different contexts. Gender can therefore be seen as 'contingent and fluid' (Sunderland, 2004: 19), and it is more constructive to talk about the existence of a multiplicity of gender identities, or the 'masculinities' and 'femininities' of individuals.

Butler's (1990) theory of performativity has proven useful in conceptualising language users' relationships with their gender. It has its origins in speech act theory, which argues that certain utterances said in the right contexts cause material changes in reality, such as promises, vows, prison sentences, and so on. Butler relates this idea to gender, saying that language can construct gender, that gender is not something someone has, but rather something that they do. It is not something that is intrinsic, flowing directly from our bodies, but rather a performance that has to be constantly reiterated and publically displayed throughout our lives. People are active producers of their gender identity, but the 'highly rigid regulatory frame' (Butler, 1990: 33) within which they operate privileges some performances and punishes others. Over time, certain linguistic features and speech styles become associated with certain gender positions or identities, and are naturalized (or 'congealed'). Their socially constructed nature is 
obscured and it becomes generally accepted that 'this is just the way things are'. The constant repetition of certain behaviours by some genders functions as 'on-going gendering processes that tightly link certain bodily poses, facial expressions, hair-cuts, clothing, and even drinks with either men or women' (Milani, 2014: 5). These ways of being and behaving become signifiers of gender over time, and these signifiers are used to communicate a person's gender identity to the world. Conceptualizing gender in this way allows analysts to investigate how people negotiate or resist the gender norms placed on them by culture and society by focusing on the semiotic resources that people draw on to index their place on the continuum in different contexts and for different means. The drag kings in this study are thus able to fashion their acts, personae, and costumes from signifiers that are closely linked to men and masculinity.

According to Halberstam (1998), the subversive power of the drag act lies in the fact that drag parades discontinuities between gender and sex or appearance and reality, but does not allow these discontinuities to be read as dysfunction (as they would be in ordinary circumstances). Instead, these inconsistencies become a site of gender creativity. Unlike the male impersonator, whose goal is to pass as male - whose act is an attempt to pull off a plausible 'male' performance - drag kings do not simply mimic or imitate men. They often seek to parody and disrupt mainstream, dominant forms of masculinity, by showing that they are not natural, 'real', or stable, as they are believed to be, but purely performative. Drag performances function as a sub-cultural practice that attempts to disturb conventional beliefs about gender expression.

\section{Cultural performances and entextualisation}

Drag king performances are less like the quotidian identity performances discussed by Sunderland, Baker and Butler above, and are more like what Coupland (2007) terms 'high performance' and what linguistic anthropologist Richard Bauman (1992) calls 'cultural performances'. According to Bauman (1992), cultural performances are communicative events during which performance is the most important mode of communication. In these occasions, the communicative act is put on display for an audience, and is thus objectified and able to be intensely scrutinized. In order to be recognized and interpreted correctly, such events are keyed or framed in specific ways - they are scheduled to take place at a specific time; they are temporally bound with a clear beginning and end point; they are spatially bound, occurring within the confines of a set place; and they follow a pre-organised programme. In other words, they are highly coordinated and public occasions. According to these criteria, it is clear that these drag king's stage performances can be considered cultural performances, and that the audience is meant to objectify and pay special attention to these performances of masculinity.

High performances are also able to do critical work through decontextualisation (Coupland, 2007). How this works becomes clear once we think about the emergence of normative ideas around gender using Bauman and Briggs' concept of entextualisation. Entextualisation is the process whereby culture and cultural norms come into being through the continual laying down or sedimentation of 'texts', or ways of speaking and interacting, until they 
become common speech genres (1990: 73). This mirrors Butler's assertion that gender is 'a set of repeated acts within a highly rigid regulatory frame that congeal over time to produce the appearance of substance, of a natural sort of being' (1990: 33). High performance events like the drag king show contribute to entextualisation and build on cultural meaning because they too (re)produce texts. However, they also decontextualise the existing texts that they draw on, as they transfer them from their original contexts into a new context - that of the theatrical performance. In doing so, the audience is also temporarily transferred away from the context of the performance and into the context to which the text being drawn upon originally belongs. This movement between contexts then allows the performance of the cultural forms to exist both inside and outside of the culture, and this distance allows the participants to reflect on or think critically about things usually taken for granted or made invisible through normalisation.

While the kings' performances on Facebook are not considered cultural events by Bauman's definition, his theory of entextualisation - with its related processes of decontextualisation and recontextualisation - is still applicable here. More specifically, it is a useful analytical tool for exploring the relationship between the two spaces in which the kings perform. According to Leppänen, Kytölä, Jousmäki, Peuronen, and Westinen (2013), entextualisation is a key resource for identity performances online, particularly in social media environments. In their study, they examine five cases from different social media platforms in which users extract (or decontextualise) discourse material - or 'instances of culture' (Leppänen et al., 2013: 7) - from elsewhere, and then modify it while integrating it into the new context (recontextualisation), in order to communicate something meaningful about their identities. A similar process is at work on the Facebook pages of the members of Bros B4 Ho's. The kings decontextualise discourse and semiotic material originating in their live performances, and then reposition them online, opening them up to scrutiny from a much wider audience than would be found at one of their events. The material they choose to draw upon to share on Facebook can be seen as key moments of their performances which they wish to emphasise, moments that they think are emblematic of the identities and masculinities they are attempting to portray through their personae. This means that their performances in the virtual domain constantly make intertextual references to their stage performances. The most obvious example of this process occurs when the kings post video clips of their acts onto their pages, which allows their performances to continue outside the spatial and temporal boundaries of the events in a format that fits the new context.

What follows is a multimodal analysis of data taken from the kings' Facebook pages which demonstrate their performances of masculinity as well as the use of entextualisation as a resource for identity performances online.

\section{DATA COLLECTION AND ANALYSIS}

Data was collected from July 2012, when the group's first formal show was held, up until November 2013. In order to observe the troupe's Facebook activity, I 'liked' the group page and each of the individual kings' pages to ensure 
that updates to any of the pages would show up in my own news feed. Further than this, I did not participate and refrained from commenting on posts, posting to the page or engaging in any kind of discussion. I merely observed, and captured screenshots of interesting or relevant occurrences relating to selfpresentation specifically with regards to gender. I also used the Facebook pages to collect any online newspaper articles about or interviews conducted with the kings, as they regularly shared links to such content with their fans. Preliminary analysis of the data was supplemented by conducting a face-to-face semi-structured interview with the founder of the troupe, Catherine Saint Jude Pretorius. This interview was used as a method of data collection to explore more deeply a few of the issues that had come up in the data, as well as to gain clarity on a few issues.

In order to investigate to what extent normative ideas about gender are overturned or reproduced in the data, multimodal discourse analysis was used as an analytical tool. Multimodality entails considering semiotic resources beyond speech and writing - such as images, video, sound, and more - and trying to understand how the complex interaction between these different semiotic modes communicates meaning (see Kress and van Leeuwen, 2006). This approach proved the most useful since much of the data collected on Facebook, such as photographs and video clips, is multimodal in nature. In addition to this, I have tried to understand the 'affordances' (Kress and Van Leeuwen, 2006) that the platform provides for a gendered identity performance. Kress (2010) explains that each technology that is used to create and communicate meaning has affordances, in that it facilitates some forms of meaning-making and inhibits others. These affordances then shape the way we communicate and perform identity.

Discourse analysts base their analyses on the understanding that any text created is ideological because text producers constantly have to make certain semiotic choices and not others - consciously or unconsciously - when representing an aspect of reality. As analysts, we try to understand how and why certain semiotic resources have been used in a text to define reality in a certain way, and what the ideological implications of these choices might be (see Cameron, 2001). This study attempts to decode the discursive and semiotic choices made by the kings in the performance of masculinity online. This will provide insight into the ideologies of gender and masculinity that inform their performances, and allow us to gauge to what extent these performances prompt viewers of the Facebook pages to reflect critically on discourses and ideologies of gender that have become naturalized. The data presented in this section focuses in particular on profile and cover pictures, and the biographical 'About' section of several of the kings' Facebook pages.

\section{Drag kings on Facebook}

Facebook profiles and pages currently take the form of Timelines: they present a reverse-chronological log of a user's Facebook activity with the most recent activity at the top. They are usually headed by the user's name, along with a profile picture and cover photo. The profile picture is the smaller image, and it is also the one that appears alongside the user's name whenever they are active anywhere on Facebook. It is the visual element that allows people to recognize each other easily on the platform. The 
cover picture is a much larger image that appears only at the top of one's profile. In their 'Help' section, Facebook describes the cover as 'your chance to feature a unique image that represents who you are or what you care about'. ${ }^{1}$ Profile and cover pictures are both automatically set to the 'Public' privacy level, so that users who are not as yet connected can search for and recognize each other. This is where we will focus our discussion of the visual elements of their online performance, as these images are usually the first thing that a user will see when they visit one of these pages. I will also be examining the biographical 'About' section, where users can present a written statement to give more in-depth information about themselves.

\section{Saint Dude's profile picture}

The profile picture that appears on the page of rapper Saint Dude, the leader of Bros B4 Ho's (figure 2) is a studio photograph of himself in character, accompanied by two women dressed in little black dresses and posed to appear very traditionally feminine. Entextualisation is evident throughout the profile in the fact that elements of a drag persona's 'personality' sometimes come through in the content they share on their pages. When asked about how she decided what would go onto Saint Dude's Facebook page, Pretorius replied,

I thought about like (.) if my charac- if I was Saint Dude, like what would Saint Dude be posting? He'd be posting pictures of himself with other women, and you saw on my page, I had pictures of me with women, with condoms in my pockets, and like (.) me posing in the middle [...] That's the kind of thing I thought Saint Dude would (.) post.

The profile picture thus becomes a way for the performer to visually portray aspects of Saint Dude's persona that would usually be performed on stage.

The photograph also effectively demonstrates the strategy of masculine supplementarity (Halberstam, 2001: 428), when a hyperfeminine woman or drag queen joins a drag king performance to both supplement the king's masculinity and destabilize it by highlighting anything he lacks. This technique is used on several occasions in the stage performance data I collected, most notably in Frankie's performance of Baby Got Back. ${ }^{2}$ In the Facebook data here, the practice of having female performers assist a king's performance of masculinity is lifted from the context of the stage and repositioned and recontextualised here in the form of a profile picture. The presence of the hyperfeminine women in this picture emphasises what is lacking in the king's masculinity, as it highlights the fact that Saint Dude is noticeably shorter than his companions. However, their presence also makes up for this lack: their exaggerated femininity boosts his masculinity by positioning him as clearly not feminine.

Along with their clothing, the king and the women use their poses and facial expressions to index stereotypical associations of masculinity or femininity. Saint Dude poses quite rigidly, keeping his body tense, with a deadpan expression on his face. It is very likely that this control over the body and expression is an attempt to exhibit an air of 'seriousness' and associations of reason linked with stereotypical masculinity.

${ }^{1}$ https://www.facebook.com/help/388305657884730/ (Accessed 20/02/2014).

${ }^{2}$ Frankie H (I Like Big Butts) https:/www.youtube.com/watch?v=cTF-7GZkzAA 


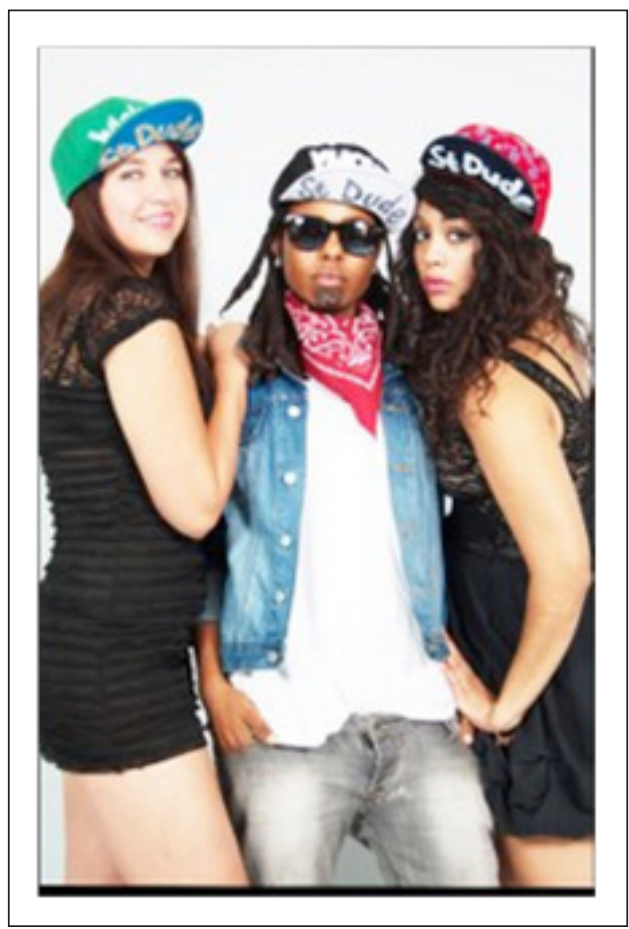

Figure 2 - Saint Dude's profile picture

In fact, all the other drag kings in the troupe also have serious, unsmiling expressions in their profile pictures on display at this point. In the interview, Pretorius also explained that some of the drag king tutorials the group consulted on Youtube recommended clenching the jaw rather than smiling in photographs, because smiling causes one's cheeks to go up and one's face to look rounder, and thus more feminine.

The king is also facing directly towards the camera with his hands in his pockets. This makes his body appear angular, and allows him to take up more space in the picture. If we compare this to how the women are standing, we see that they are both showing one side of their bodies to the camera. This pose ensures that the curves of their backs, shoulders, arms and legs are on display, and that their bodies take up less of the frame. The bodies of the two women are also a lot less rigid than Saint Dude's - their arms and hands are draped loosely over his shoulders. This is effective because things that are angular bring to mind hardness, traditionally associated with masculinity, whereas things that have curves suggest softness, which is generally linked to femininity. The women also look coyly over their shoulders at the camera, the one smiling and the other pouting with a wide eyed expression. These facial expressions, the clothing, makeup and the way they hold their bodies are all geared towards indexing 'sexiness', which indicates that the women are meant to evoke associations of traditional heterosexual female sexuality.

The women's presence in the picture is also a means for the king to perform heterosexuality - an important aspect of dominant masculinity - as it presents him not only as a heterosexual man who would desire them, but also as a man who is clearly desired by them. The women are draped over his body, and though they are looking at the camera, their bodies are directed inward towards him. They keep their bodies and faces close to his - one woman has her leg slightly over his, while the other keeps her hand over his hand and her breasts touch his body. In addition to their posture, both women sport copies of Saint Dude's signature baseball cap with his name emblazoned underneath the visor, in the manner of fans emulating an idol. The viewer's attention is drawn to these when looking at the women, as the caps are the only colourful item of clothing they wear. It is clear that the king's companions in this image are meant to mimic and parody the sexy, nameless and ultimately dispensable women that form part of a famous, wealthy rapper's entourage. 
We now turn to an examination of drag king FreDDie's profile, where the process of entextualisation is most noticeable.

\section{FreDDie's profile and cover picture}

As his name suggests, FreDDie is a Freddie Mercury impersonator, who bases his look and performances on the lead singer of the famous British band Queen. He generally performs medleys of the band's most famous songs, and his costume is designed to allow his audience to recognize the mimicry. He often sports a decorated black blazer similar to the caricature of a military jacket worn by Mercury at his birthday party in Munich in 1985. He also wears large shades and a thick moustache, usually with his hair slicked back (figure 4).

The cover picture on on FreDDie's Facebook page highlights examples of entextualisation of entextualisation (figure 6). It is a black and white image featuring FreDDie in his jacket standing on rocky terrain, right arm raised in the air, hand in a fist, with a cloud-covered
Table Mountain in the background. He does not face the camera, but looks off into the distance. Since he is not looking directly at the viewer, this is an 'offer' image (Kress and Van Leeuwen, 1996: 124), and requires the audience to do nothing but observe.

This is also a pose that I saw FreDDie perform twice at the show at Obz cafe, during his rendition of Queen classics The Show Must Go On and We Are the Champions (figure 7). Viewers who are even only vaguely familiar with Queen will recognize the stance as reminiscent of the famous pose Mercury often struck on stage during live performances (figure 8). In this picture, FreDDie is decontextualising a well-known element of Freddie Mercury's performances - a movement - and integrating into his stage act, and then taking this material from his stage performances and recontextualising it again, this time as an image, to fit into his Facebook page. This process is repeated in much of what FreDDie performs, and as a result, his page is full of intertextual references, both to the celebrated singer and to his own performances.

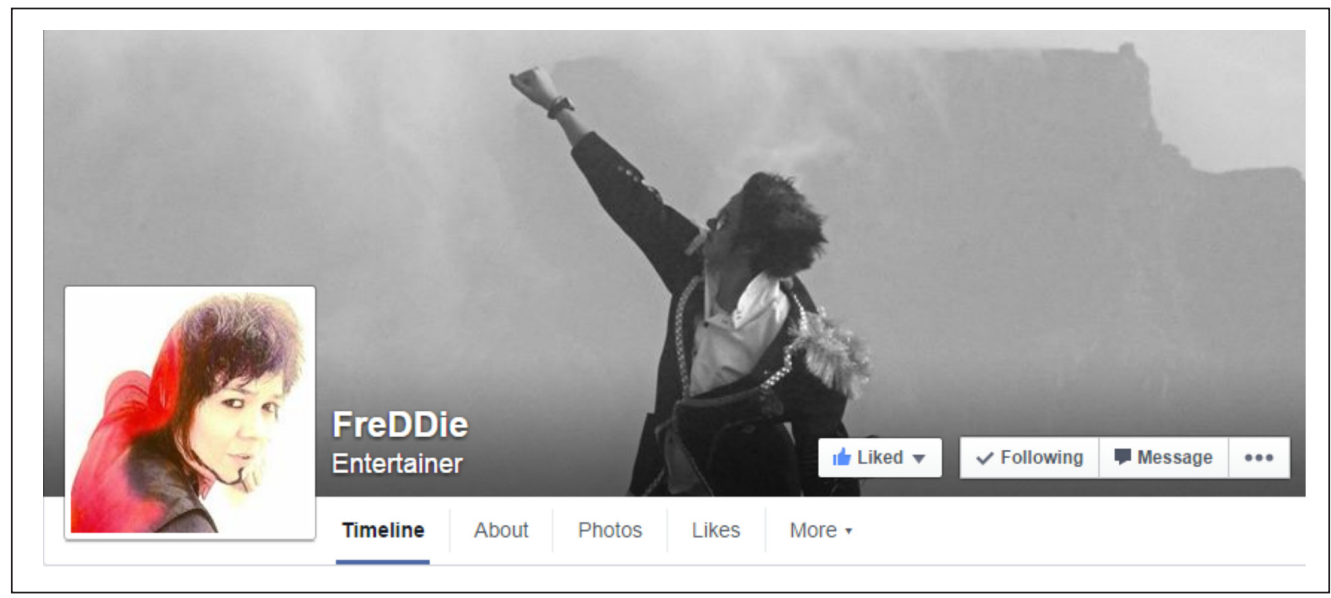

Figure 3 - FreDDie's page header 


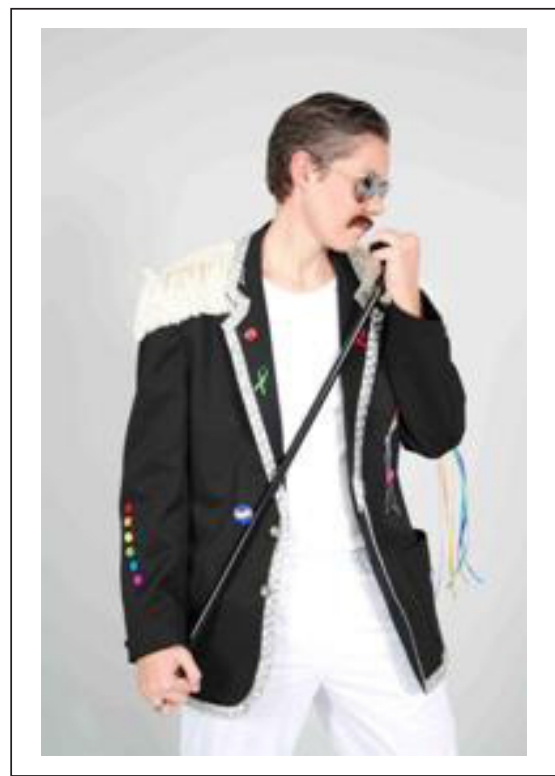

Figure 4 - FreDDie's look

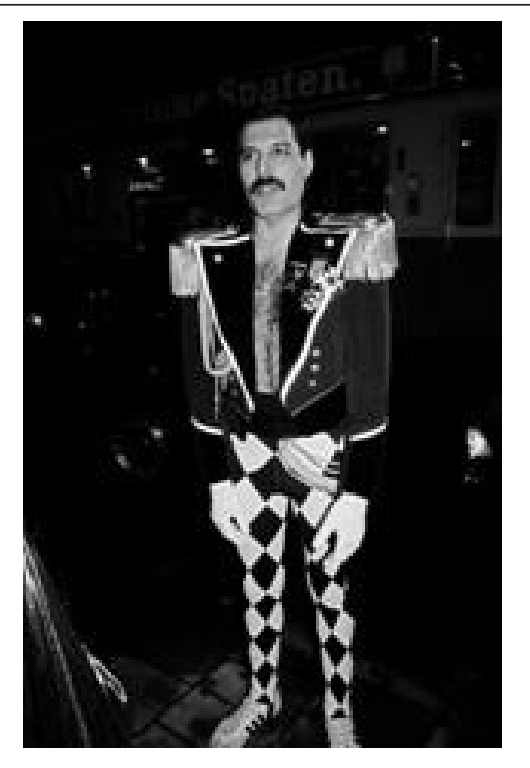

Figure 5 - Freddie Mercury at his birthday party at the Hilton Hotel in Munich, Germany, 1985 $^{3}$

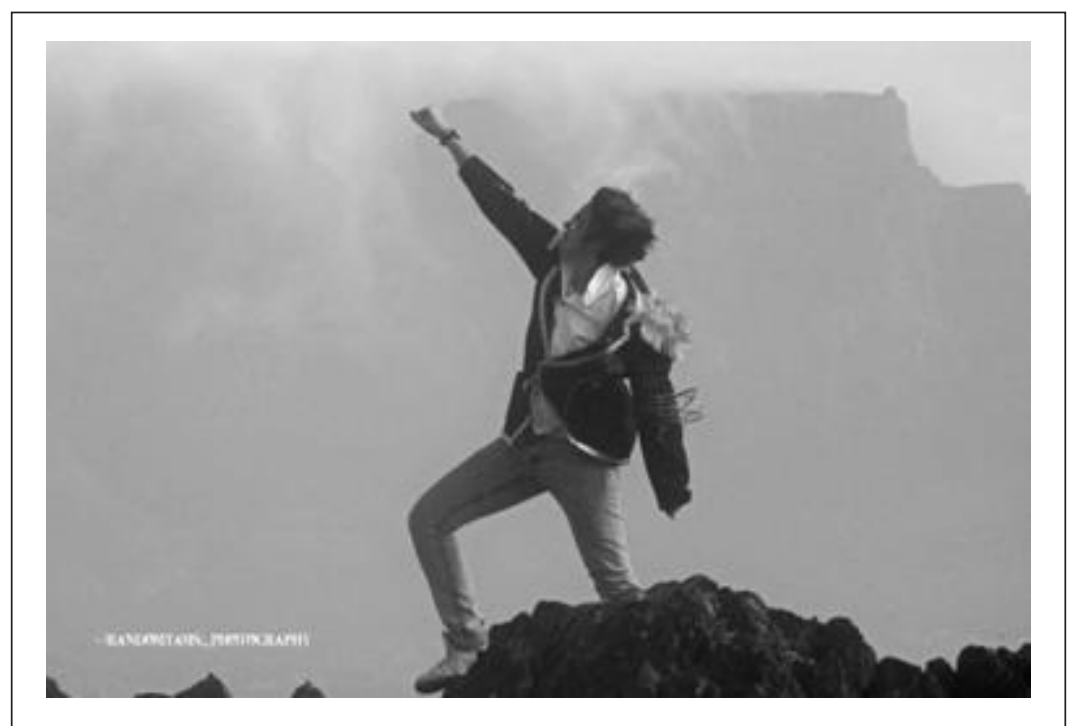

Figure 6 - FreDDie's cover picture

${ }^{3}$ Photo by Richard Young / Rex Features ( 458742ea ). Source: http://wewillrockyou.pl/foto/freddiemercury-1980-86/shooting-stars-30-years-of-the-photography-of-richard-young/ Accessed: 28/02/2014 
FreDDie's pose in his cover picture is more than just an allusion, however. The raised fist is also significant in that it brings to mind a salute that is often used as a gesture of protest (such as the feminist fist and the Black Power salute) and has become a symbol of power, resistance and defiance. The fact that he is standing against the wind - which we can tell from the direction his hair is blowing - contributes to these connotations. In addition to this, FreDDie's gaze is directed up into the upper left corner of the frame. Machin and Mayr (2012) explain that when a person looks off frame, they are being made to look thoughtful, and the viewer is being invited to imagine what they are thinking. When the gaze is directed slightly upwards, the connotations of 'up' are triggered - the person in the image is presented positively, as looking forward, towards the future or up to 'lofty ideals' (2012: 73). Furthermore, the closeness of

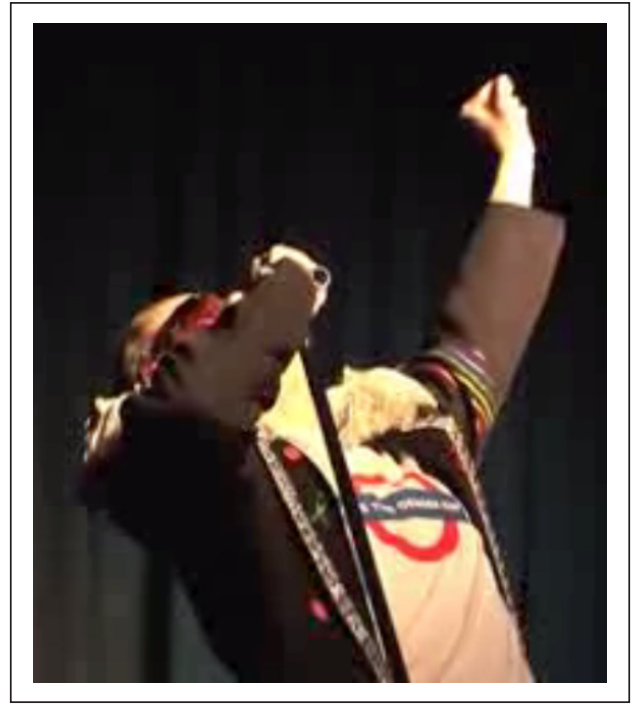

Figure 7 - FreDDie mid-performance the mountain behind him along with the clouds and the wind allows the viewer to see that FreDDie is standing somewhere high up. This height complements the connotations triggered by the upward direction of the king's gaze. The fact that FreDDie's cover picture does not appear in colour is also significant. Black and white images are a symbol of the past, so choosing to create a modern photograph in this style may be an attempt to trigger feelings of nostalgia for a bygone era in the viewer. Using Table Mountain specifically as the backdrop links the image to South Africa and situates FreDDie in Cape Town. FreDDie's cover picture thus presents him as powerful and defiant, looking forward with optimism, and we could also argue that it contains a figurative salute along with the literal one - it is a salute to his idol, a reminder that his performance is a tribute to an icon he admires.

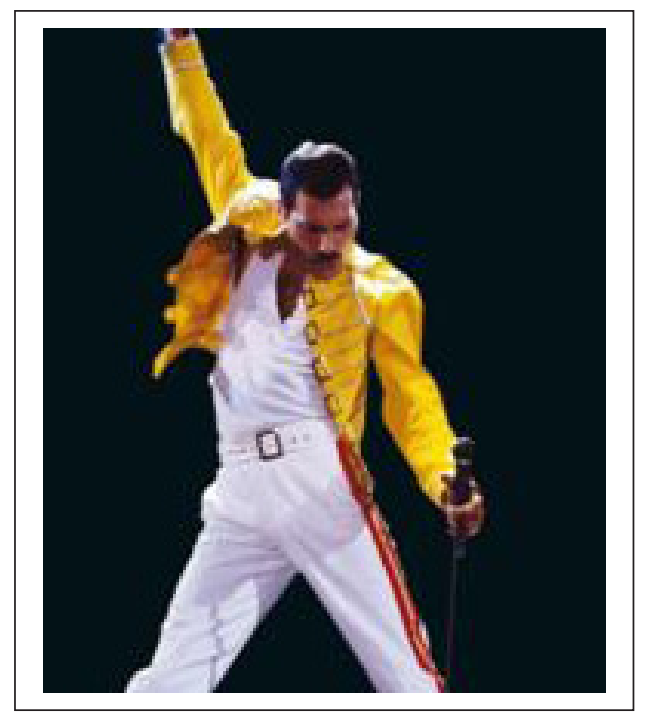

Figure 8 - Mercury during Queen's live performance at Wembley Stadium, $1986^{4}$

\footnotetext{
${ }^{4}$ Source: http://89millionand7.blogspot.com/2012/11/but-he-collected-postage-stamps.html Accessed 28/02/2014.
} 
The next section will focus on a more text-oriented element of the Facebook page. In contrast to the kings' profile pictures, the Biography feature in the 'About' tab of their pages allows them to make much more explicit statements about themselves or their personae in ways they might not normally do on stage or in interaction. Examining these texts could give us insight into further ways the kings negotiate their drag subjectivities online.

\section{Frankie H's 'About' section}

It is important to note first that it is generally understood by Facebook users that the biographical statements that appear in these sections have been written by the owner of the profile or page, despite the use of the third person. What is interesting with the kings' biographies is that there is an extra level, in that it is understood by the viewer that it is the performer behind the persona who is the author of the text, and who is performing the drag king writing about himself in the third person. The biography will then be read as another part of the king's costume and an extension of his act. Frankie H's biography, for example, reads as follows:

\section{Extract 1:}

Frankie $H$ is a drag king who started in Cape Town, SA, with Bros B4 Ho's and now performs in Trondheim, Norway. He likes to dance like everybody's watching.

Frankie $H$ comes from the deep American South and isn't ashamed of it. For the last seven years, he's been touring the world in search of extraordinary cultures and mind-blowing sex. On stage, Frankie likes to show off his love for the ladies with somewhat erotic and undeniably crude song performances. Don't be fooled, though - somewhere underneath his rough, macho, arguably misogynistic exterior lies the heart of a warm, fuzzy puppy that loves a good belly rub. ${ }^{5}$

A closer examination of the extract gives us insight into the kind of masculinity Frankie is attempting to perform. The second sentence 'He likes to dance like everybody's watching' - sets the tone for the text. It is a humorous play on the saying 'Dance like nobody's watching', which is meant to encourage people to overcome their self-consciousness and enjoy themselves without the fear of being judged by others. Frankie's version suggests that, by contrast, he revels in the presence of an audience. Phrases such as 'on stage', 'show off' and 'exterior' hint at the centrality of drama and performance to his personality. However, not only is Frankie constantly aware that he is putting on a show, but it is also clear here that he is conscious of the type of masculinity he is performing. By mentioning 'his love for the ladies' and his world-wide quest for 'mind-blowing sex', he implies that he is heterosexual and promiscuous. He also goes on to describe himself as 'crude', 'rough', 'macho'. One could argue that, by trying to come across as a virile and boorish man, he is attempting to channel a normative, mainstream type of masculinity.

There is more to it than that, however. What is most interesting about Frankie's biography is that there is an element of self-criticism underlying his depiction of himself. The choice of

\footnotetext{
${ }^{5}$ https://www.facebook.com/FrankieHardon/info?tab=page_info (Accessed 09/12/2014).
} 
the terms 'rough' and 'macho', as well as the declaration of promiscuity and heterosexuality, are descriptions that one might expect a man performing this type of masculinity to use quite proudly. But he talks about his song performances rather unfavourably, calling them 'somewhat erotic and undeniably crude', which seems slightly out of character. Using the word 'somewhat' - which means 'to a limited degree' - to modify 'erotic' implies that the king's performances are not as sexy as he would like them to be. Similarly, we can assume that he would rather his serenades be 'smooth' or 'suave' than 'undeniably crude'. Frankie is using this unexpected and humorous account of his performance to mock and poke fun at himself, and by extension, the type of masculinity he performs. In a similar way, he admits that he is 'arguably misogynistic', which is unusually selfreflective. By doing so, the king makes it clear that his performance is not a wholesale, uncritical reproduction of a problematic type of masculinity, but rather a light-hearted way of engaging with it.

The final sentence of the extract is also particularly intriguing and worth discussing. The phrase 'Don't be fooled, though' makes the reader believe that there is about to be some kind of revelation, that the king thinks his biography may have led the reader to see him in a certain way, and he is about to confess something different. He makes it seem as though he is about to peel back a layer of his costume ('underneath his ... exterior'). We are led to believe that we are about to see the woman behind the performance, but by the second part of the sentence we realise that we have been denied. This playful teasing is very similar to theatrical layering, a term coined by Halberstam to describe a drag king technique she observed in her research on drag kings. Theatrical layering involves the king doing a striptease on stage, misleading the audience into believing that the woman underneath the costume will be exposed. Instead, another male persona is revealed, and the audience then questions the belief that hidden under the male image is a 'true' form, a 'real' woman. The fact that Frankie tries to convince us that deep inside he really is a playful and cute puppy that wants love and attention - contradictory to his 'macho' outside - makes the 'exterior' seem more like an act than ever, and serves as a reminder to the audience that masculinity - and gender more broadly is a performance for all of us, not just for drag kings on a stage.

\section{Gender trouble}

The above analysis highlights that the kings make use of the various affordances Facebook allows for selfpresentation in order to evoke masculine personae. However, it is important to note that the drag king acts on Facebook do not simply attempt to present the most 'authentic' performance of masculinity possible, but are shaped by the double meaning afforded by the drag performance in general. The reproduction of masculinity is troubled by the audience's knowledge that there is a non-male-bodied person behind each performance. This extra layer of meaning contributes to disrupting the normative scripts of masculinity evoked in these performances in interesting ways.

The first and arguably most important work that this troubling knowledge does is that it makes the performativity of gender visible. By demonstrating that successful performances of masculinity can 
be produced by people who are not men, it denaturalises masculinity, bringing attention to all the props and strategies that are needed to perform it successfully (Milani, 2014). In doing so, it also disrupts the 'coat-rack' model of gender (Nicholson, 1994): the idea that gender maps directly on biological sex, and that masculinity flows naturally from male bodies, and femininity from female bodies.

However, while the reproductions of masculinity are troubled by the audience's awareness of the non-malebodied performer, it is important to acknowledge that reproduction is taking place. Although the drag performances do successfully disrupt mainstream ideas about gender, in relying on recognizable, stereotypical signifiers of masculinity to do so they reproduce and reinforce them even as they are overturning them. They contest and collude with problematic, normative scripts of masculinity simultaneously. Saint Dude's profile picture (figure 2) above is a noteworthy instance of this tension between subversion and reproduction. On the one hand, the presence of the women in the picture can be read as part of the kings' parody of the sexism and objectification of women that takes place in the hip hop industry. In addition, the inclusion of the women is a strategy to make fun of masculinity by pointing out, as Halberstam (1998) does, that it relies on props, that even a misogynistic figure like Saint Dude is actually dependent on the women he treats as unimportant and dispensable, and would be a lot less masculine without them there. At the same time, however, the performer playing Saint Dude is objectifying these women as much as her character is, because she is using their bodies as props, not only to complete her rapper persona, but also as tools to boost her own performance of masculinity. Therefore, the performance is not a purely straightforward disruption of heteronormative masculinity; part of it reproduces and reinforces the very structures it seeks to critique.

A similar ambivalence is discussed in Milani's (2014) examination of an artwork that formed part of the Queer and Trans Art-iculations exhibition at Wits Art Museum in 2014. It focuses on the way the drawing and narrative of a transgender individual posing bare-chested challenges the gender binary while reinforcing it. The way the individual poses in the painting and the use of pronouns in the narrative work together to align the gender presentation directly with male-masculinity. However, this alignment is troubled by what is generally considered a female bodily presence - the breasts that dominate the portrait. According to Milani,

'the multimodal and multivocal arrangement of this work of art embodies a tension between, on the one hand, attempts to overcome identity categories altogether, and, on the other hand, the co-existence of gender identities which are simultaneously conventional and radical.' (2014: 7).

This portrait and these online performances by Bros B4 Ho's demonstrate the complexity of resistance to the gender binary, but also have implications for the theory of female masculinity. Halberstam describes female masculinity as a purely subversive phenomenon, and maintains that she is "using the topic of female masculinity to explore a queer subject position that can successfully challenge hegemonic models of gender conformity.' (1998: 9). However, we have demonstrated that 
these performances of masculinity by women do not automatically trouble the gender binary or challenge hegemonic beliefs about gender. Furthermore, what we have concluded about Bros B4 Ho's confirms Lucy Jones' (2013) problematising of the term female masculinity. Her criticism of the concept lies in the fact that it reuses categories from a binary that sets masculinity up as existing in opposition to femaleness by definition. As she explains, 'hegemonic masculinity $[\ldots]$ is relational, existing in opposition to women and homosexuals' (2013: 4). Even though masculinity is a construct that can be performed, she argues that it is too closely linked ideologically to maleness to be easily applied to female bodies. She believes that simply reapplying the two categories from a problematic binary to look at nonnormative gender presentations could cause us to misunderstand them. If we return to the drag performances under discussion, we have seen that there is much complexity and ambivalence in what the kings are doing - it is neither straightforward reproduction nor complete subversion, but a tense combination of the two. By terming drag king performances female masculinity as Halberstam does, we risk glossing over this complexity.

Taking this ambiguity into account, can we establish whether or not the masculinities put on display by these kings are in fact 'queer subject position[s]'? Jagose explains that queer endeavours work to question 'normative consolidations of biological sex, gender and sexuality' (1996: 99). A queer project thus tries to disentangle the straightforward alignment of gender with biological sex (i.e. female $=$ feminine and male $=$ masculine), and to expose how this understanding is made to seem normal and commonsensical. It is clear from our analysis of the data above that the kings successfully overturn the above commonsense understanding of the relationship between sex and gender by demonstrating that behaviour normally linked with masculinity can successfully be produced by non-malebodied individuals. However, queer also refers to 'a critical practice in which nonnormative [genders] and sexualities infiltrate dominant discourses to loosen their political stronghold' (Hayes, 2000: 7). While the kings do denaturalise the mapping of gender directly onto sex - and that is a queer exercise - we have noticed that, in doing so, they reproduce normative forms of masculinity. They decide that certain behaviours are prototypical of masculinity and reproduce those. Of course, this is necessary to some degree in order for the audience to be able to recognize their gender performances as masculinity, but we have to acknowledge that by doing this, they reinforce the belief that these versions of masculinity are 'normal'. This strengthens rather than loosens the political stronghold of dominant discourses around masculinity.

At one point in the interview, Pretorius uses the phrase 'I beat them at their own game' to describe the success of her performances as a black woman in a space that is often seen as inaccessible to black women (the white male drag bar). This statement neatly encapsulates the paradox above. To find a way to succeed at a game which is designed so that you usually lose requires that you 'play the game' in the first place. It requires that you be complicit in an oppressive system,

${ }^{6}$ Emphasis added. 
rather than stepping out of it entirely. Perhaps such complicity is inescapable when engaging in a critical project, because it is necessary to reference the object of one's criticism. Even so, while the kings' success at resistance should not be diminished, their collusion with the systems they are resisting should not be ignored either.

So then, is it possible that the performances by the kings of Bros B4 Ho's are queer and not queer at the same time? We should bear in mind that different readings of a text can co-exist, and that choosing one reading over another may be too simplistic and would erase the complexities and interesting tensions we have uncovered in their work. As Jagose reminds us, 'queer is a category in the process of formation [...] its definitional indeterminacy, its elasticity, is one of its constituent characteristics' (1996: 1). Perhaps it is this very elasticity that allows it to apply to a situation such as this.

\section{CONGLUSION}

This study aimed to examine the Facebook pages of the drag king troupe Bros B4 Ho's in order to demonstrate that the performers continue their theatrical performances on an online platform primarily through the process of entextualisation, in which they draw on material from their stage acts and then recontextualise it online. Furthermore, this study has revealed that while drag king performances are effective at troubling ideologies of gender, their subversive work is limited in that they rely on the very concepts they critique for their message to be understood. I have thus argued that, in light of this data, Halberstam's conception of female masculinity as a purely subversive phenomenon needs rethinking. All in all, this study has attempted to remedy the lack of sociolinguistic research into theatrical performances of masculinity by women through a detailed investigation into the online activity of South African drag troupe Bros B4 Ho's.

\section{REFERENGES}

Baker, Paul. 2008. Sexed Texts: Language, Gender and Sexuality. London: Equinox.

Barrett, Rusty. 1995. Supermodels of the world, unite! Political economy and the language of performance among African American drag queens. In William L. Leap (ed.), Beyond the Lavender Lexicon: Authenticity, Imagination and Appropriation in Lesbian and Gay Languages. New York: Gordon and Breach Press.

Barrett, Rusty. 1999. Indexing polyphonous identity in the speech of African American drag queens. In M. Bucholtz, A.C. Liang, and L. Sutton (eds.), Reinventing identities: The gendered self in discourse. New York: Oxford University Press.

Bauman, Richard. 1992. Performance. In R. Bauman (ed.), Folklore, Cultural Performances, and Popular Entertainments: A Communications-centered Handbook. New York: Oxford University Press.

Bauman, Richard and Charles Briggs. 1990. Poetics and performance as critical perspectives on language and social life. Annual Review of Anthropology. 19: 59-88.

Butler, Judith. 1990. Gender Trouble: Feminism and the Subversion of Identity. New York: Routledge.

Cameron, Deborah. 2001. Working with Spoken Discourse. London: Sage.

Coupland, Nikolas. 2007. Style: Language variation and identity. Cambridge: Cambridge University Press.

Halberstam, Judith. 1997. Mackdaddy, superfly, rapper: Gender, race, and masculinity in the drag king scene. Social Text, 52/53: 104-131. 
Halberstam, Judith. 1998. Female Masculinity. Raleigh: Duke University Press.

Halberstam, Judith. 2001. Oh behave! Austin Powers and the Drag Kings. GLQ: A Journal of Lesbian and Gay Studies, 7(3): $425-452$.

Hayes, Jarrod. 2000. Queer nations: marginal sexualities in the Maghreb. Chicago: University of Chicago Press.

Kress, Gunther. 2010. Multimodality: A social semiotic approach to contemporary communication. London: Routledge

Kress, Gunther, and Theo Van Leeuwen. 2006. Reading images: The grammar of visual design. (2nd ed.). London: Routledge.

Jagose, Annamarie. 1996. Queer Theory: An Introduction. New York: New York University Press.

Jones, Lucy. 2013. Masculinity in lesbian discourse: The case of butch and femme. Unpublished manuscript.
Leppänen, Sirpa., Samu Kytölä, Henna Jousmäki, Saija Peuronen, and Elina Westinen. 2013. Entextualization and resemiotization as resources for (dis) identification in social media. Tilburg Papers in Cultural Studies, 57.

Machin, David and Andrea Mayr. (2012). How to do critical discourse analysis: A multimodal introduction. London: Sage.

Milani, Tommaso M. 2014. Querying the queer from Africa: Precarious bodies precarious gender. Agenda: Empowering women for gender equity

Nicholson, Linda. 1994. Interpreting gender. Signs. 20(1): 79-105.

Sunderland, Jane. 2004. Discourse, Discourse Analysis and Gender. Gendered Discourses. Basingstoke: Palgrave Macmillan. 